\title{
Colon or Rectum Neuroendocrine Tumor pT1a TNM Finding v7
}

National Cancer Institute

\section{Source}

National Cancer Institute. Colon or Rectum Neuroendocrine Tumor PT1a TNM Finding v7. NCl Thesaurus. Code C90104.

Colon or rectum neuroendocrine tumor invading lamina propria or submucosa and is less than $1 \mathrm{~cm}$ in greatest dimension. (from AJCC 7th Ed.) 